\title{
Atypical presentation of type A aortic dissection: a case report
}

\author{
Nela Kostova'*, \\ Magdalena Otljanska', \\ Igor Kostov² \\ University Clinic of \\ Cardiology, Skopje, \\ Republic of Macedonia \\ ¿University Surgery Clinic \\ "St Naum Ohridski", Skopje, \\ Republic of Macedonia
}

\author{
KEYWORDS: aortic dissection, atypical symptoms. \\ CITATION: Cardiol Croat. 2015;10(9-10):215. | DoI: http://dx.doi.org/10.15836/ccar.2015.215
}

*ADDRESS FOR CORRESPONDENCE: Nela Kostova, University Clinic of Cardiology, 1000 Skopje Republic of Macedonia. Phone: +389-70363896 / E-mail: nelakostova@yahoo.com

ORCID: Nela Kostova, http://orcid.org/0000-0003-1845-3756 • Magdalena Otljanska, http://orcid.org/0000-0003-0190-9710 Igor Kostov

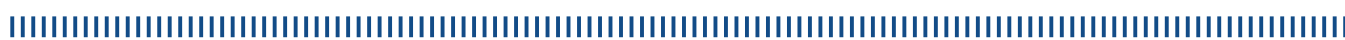

BACKGROUND: Aortic dissection typically presents with severe chest or back pain. Lower limb ischemia occurs in less than $10 \%$ of cases of type A aortic dissection. Isolated distal limb ischemia as the first sign of dissection is very rare. ${ }^{1-3}$

CASE REPORT: A 75-year-old man with history of uncontrolled hypertension and smoking was admitted to our hospital with sudden onset of lower extremities pain. During exertion patient felt transient mild chest pain. He was asymptomatic few hours till onset of sharp pain in his left leg. He was admitted in our hospital with persisting symptoms and sings of critical distal limb ischemia. There was significant systolic blood pressure difference. Troponin T was negative, but other cardiac biomarkers were highly elevated. Transthoracic echocardiography detected aortic root dilatation, mild regurgitation and aortic arch intimal flap. CT angiography was performed and type A aortic dissection, with doubled lumen was detected from ascending aorta to aortic bifurcation. Supra-aortic vessels were not involved and no repercussion on celiac, renal or mesenteric artery flow was detected. Thrombus in left iliac artery with involvement of left external iliac artery could explain signs of distal limb ischemia. Patient was referred to cardiovascular center but unfortunately he died immediately after transfer to surgical institution.

DISCUSSION AND CONCLUSIONS: Aortic dissection is an emergency that, unless it is quickly identified, almost regularly results in death, especially in presence of atypical or rare symptoms. Suddenonset of lower limb pain or signs of critical ischemia could be the signs of acute aortic disease and should be carefully investigated.

\section{RECEIVED:}

July 29, 2015

ACCEPTED:

September 17, 2015

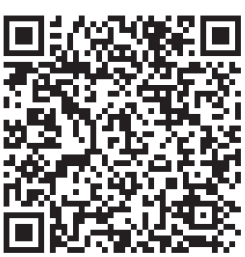

LITERATURE IIIIIIIIIIIIIIIIIIIIIIIIIIIIIIIIIIIIIIIIIIIIIIIIIIIIIIIIIIIIIIIIIIIIIIIIIIIIIIIIIIIIIIIIIIIIIIIIIIIIII

1. Erbel R, Aboyans V, Boileau C, Bossone E, Bartolomeo RD, Eggebrecht H, et al; 2014 ESC Guidelines on the diagnosis and treatment of aortic diseases: Document covering acute and chronic aortic diseases of the thoracic and abdominal aorta of the adult. The Task Force for the Diagnosis and Treatment of Aortic Diseases of the European Society of Cardiology (ESC). Eur Heart J. 2014;35(41):2873-926. DOI: $h$ ttp://dx.doi.org/10.1093/eurheartj/ehu281

2. Hiratzka LF, Bakris GL, Beckman JA, Bersin RM, Carr VF, Casey DE Jr, et al; American College of Cardiology Foundation/American Heart Association Task Force on Practice Guidelines; American Association for Thoracic Surgery; American College of Radiology; American Stroke Association; Society of Cardiovascular Anesthesiologists; Society for Cardiovascular Angiography and Interventions; Society of Interventional Radiology: Society of Thoracic Surgeons; Society for Vascular Medicine. 2010 ACCF/AHA/AATS/ACR/ASA/SCA/SCAI/SIR/STS/SVM guidelines for the diagnosis and management of patients with Thoracic Aortic Disease: a report of the American College of Cardiology Foundation/American Heart Association Task Force on Practice Guidelines, American Association for Thoracic Surgery, American College of Radiology, American Stroke Association, Society of Cardiovascular Anesthesiologists, Society for Cardiovascular Angiography and Interventions, Society of Interventional Radiology, Society of Thoracic Surgeons, and Society for Vascular Medicine. Circulation. 2010;121(13):e266-369.

DOI: http://dx.doi.org/10.1161/CIR.0b013e3181d4739e

3. Charlton-Ouw KM, Sritharan K, Leake SS, Sandhu HK, Miller CC 3rd, Azizzadeh A, et al. Management of limb ischemia in acute proximal aortic dissection. J Vasc Surg. 2013;57(4):1023-9. DOI: http://dx.doi.org/10.1016/j.jvs.2012.10.079 